\title{
Assessment of Risk Factors in Hypertensive Disorder During Pregnancy: Hospital Based (KAP) Knowledge, Attitude and Practice Survey. A Key for Preventive Approach
}

\author{
Shrestha M
}

\begin{abstract}
Background: Hypertensive disorder (HDP) during pregnancy is a group of conditions featuring with high blood pressure that may lead to feto-maternal morbidity and mortality, particularly in developing countries. Aims and Objectives: To assess relationship between risk factor of hypertensive disorder during pregnancy, their self care knowledge and practice to prevent and control hypertension. Materials And Method: A cross-sectional study of 93 registered, pregnant women belonging to reproductive age group, after $20^{\text {th }}$ gestation age completed, who came for ANC checkup or admitted for hypertension management or prior to delivery in Nepalgunj medical college and teaching hospital under department of Obstetrics and Gynecology from $15^{\text {th }} \mathrm{June}$ to $15^{\text {th }}$ December 2018. Blood pressure was measured for each women at booking or at subsequent visits. Urine test for protein albumin was performed if blood pressure was elevated. Data was entered and analysis was completed using SPSS package version 20. Results: The overall prevalence of hypertensive disorder during pregnancy was $2.85 \%$ among all deliveries. Pre -eclampsia accounted $36 \%$ of the cases followed by eclampsia $18 \%$. Gestational hypertension was $21 \%$, pregnancy induced hypertension was $20 \%$ and chronic hypertension was only $5 \%$ in study population. Conclusion: Knowledge and attitude regarding lack of exercise, low salt diet, obesity and lack of rest were poor contributory risk factors. It is recommended that all pregnant women must develop knowledge about associated risk factors and ensure the application of behavioral change practices to control and prevent hypertensive disorder during pregnancy.
\end{abstract}

Key words: Blood pressure, hypertension, HDP, pregnancy, self care knowledge

\section{INTRODUCTION}

Pregnancy, also known as "gestation", a state of carrying a fetus in women's womb during period of reproductive cycle ${ }^{1}$. It is one of the joyous moment for every womanhood in natural phenomenal sequence of their life. But this art of physiological changes, however, may get distorted due to imbalance between pregnancy and their associated risk factors. Hypertensive disorder during pregnancy is one of the major complications, putting both mother and conceptus health at sake.

\section{Burden of diseases}

Everyday 830 women, approximately die from preventable causes related to pregnancy and child birth. Almost all $99 \%$ of all maternal deaths occur in developing countries, residing in rural areas and among poorer communities. Being motherhood is challenging and may associated with ill health and even deaths ${ }^{2}$.

In developed countries, $16 \%$ of maternal deaths due to hypertensive disorders. One out of third of all maternal deaths are from hypertensive disorders and young female are 3-fold increased at risk ${ }^{3}$.

\section{Address for correspondence:}

Dr. Merina Shrestha

Department of Community Medicine

Nepalgunj Medical College \& Teaching Hospital

Kohalpur, Banke, Nepal

Email: drmerycom@gmail.com

\section{Pregnancy-induced hypertension}

It occurs in about 5-8\% of all pregnancies. Although the cause of $\mathrm{PIH}$ is unknown, certain factors are associated to increase the risk of $\mathrm{PIH}$, such as young women with a first pregnancy, pregnant women younger than 20 years and those older than 40 years, women with multiple fetuses, gestational diabetics, pregnant women with preexisting hypertension or previous episodes of preeclampsia or $\mathrm{PIH}$ and pregnant women with preexisting renal disease ${ }^{4}$.

\section{Gestational hypertention}

High BP develops after week 20 in pregnancy and goes away after delivery.

\section{Pre-eclampsia}

This is also one of the serious major condition after $20^{\text {th }}$ week of pregnancy, affecting $2-8 \%$ of all pregnancies. Gestation hypertension and PIH may progress later on as severe preeclampsia. Increase systolic blood pressure $140 \mathrm{mmhgor}$ above and diastolic pressure $90 \mathrm{mmh}$ or above along with raised protein in the urine is the diagnostic feature for pre-eclampsia which can lead to serious complications for both mom and baby if not treated quickly ${ }^{5}$. Obesity has been associated with a 2-4 fold increased risk of developing pre-eclampsia in different populations ${ }^{6}$. It contributes almost $70 \%$ of maternal and perinatal morbidity and mortality rate . $^{3}$

\section{Eclampsia}

Eclampsia is the onset of seizures (convulsions) in a woman with pre-eclampsia occurring before, during, or after delivery. Most often it is during the second half of pregnancy. The 
seizures are of the - tonicclonic type and typically last about a minute. Following the seizure there is typically either a period of confusion or coma?.

\section{Chronic hypertension}

BP $\geq 140 \mathrm{mmHg}$ systolic or $90 \mathrm{mmHg}$ diastolic prior to pregnancy or before 20 weeks gestation Persists $>12$ weeks postpartum ${ }^{5}$.

\section{Degree of hypertension}

\begin{tabular}{|l|c|c|c|}
\hline $\begin{array}{l}\text { Blood pressure } \\
\text { category }\end{array}$ & $\begin{array}{l}\text { Systolic mmhg } \\
\text { (upper number) }\end{array}$ & And & $\begin{array}{c}\text { Diastolic mmhg } \\
\text { (lower number) }\end{array}$ \\
\hline Normal & $<120$ & A & $<0$ \\
\hline Elevated & $120-129$ & And & $<80$ \\
\hline $\begin{array}{l}\text { High blood pressure } \\
\text { (Hypertensive stage I) }\end{array}$ & $130-139$ & or & $80-89$ \\
\hline $\begin{array}{l}\text { High blood pressure } \\
\text { (Hypertensive stage II) }\end{array}$ & 140 or higher & Or & 90 or higher \\
\hline $\begin{array}{l}\text { Hypertensive crisis } \\
\text { (consult your Doctor } \\
\text { immediately) }\end{array}$ & Higher than 180 & And/Or & Higher than 120 \\
\hline
\end{tabular}

\section{Blood pressure categories}

Guideline for blood pressure classification according JNC 8 blood pressure ${ }^{8}$ (American Heart Association And American Stroke Association)

\section{Self-care knowledge}

In this study self-care knowledge refers to range of activities that pregnant women must have self awareness to perform healthy life style or adhering to balance diet and medication, exercising, symptoms management and taking rest. Self-care knowledge on hypertension is needed in order to change behavior and practices to be maintained their life style for controlling blood pressure ${ }^{4}$.

\section{General measurements to prevent hypertensive disorder during pregnancy}

- Low salt diet and keep body hydrate by drink at least eight glasses of water every day.

- Increase amount of protein diet, leafy green vegetables and decrease amount of junk food, fried food.

- Avoid drinking alcohol and beverages containing caffeine.

- Avoid smoking.

- Get enough sleep and plenty of rest.

- Increase physical activity or get regular exercises.

- Timely consult Doctor and get prescribed medication ${ }^{9}$

\section{Assessment of BMI}

BMI was categorized according to WHO definitions as underweight $<18.5$, normal weight $18.5-24.9$, overweight 25.0 29.9 , and obese $\geq 30^{10}$. It had been great impact in rise in blood pressure by 2-4 fold due to obesity during pregnancy. ${ }^{11}$

\section{OBJECTIVES OF THE STUDY}

- To assess factors effecting hypertension and self care knowledge among pregnant women regarding hypertension.

- To study the relationship between self care knowledge and preventive measures taken with hypertension among pregnant women.

\section{MATERIAL AND METHODS}

This is cross sectional hospital based study carried out from $15^{\text {th }}$ June 2018 to $15^{\text {th }}$ December 2018 on the basis of knowledge, attitude and preventive practices of hypertensive disorder on women who registered in Obstetric/gynaecological department of Nepalgunj medical college and teaching hospital, Kohalpur, banke. The study population includes pregnant women between reproductive age group of 15-49 years who had completed $20^{\text {th }}$ weeks of gestation and admitted for hypertension management or prior to delivery. Nonprobability convenient sampling method was applied on the basis of exclusion and inclusion criteria. Pretested, semistructured questionnaire was designed and interviewed with respondents. It was also given and asked to the visitor of patient in case of severe toxemia of pregnant women. Based on study done in BPKIHS, Nepal, considering $27.1 \%$ as prevalence of hypertensive disorder during pregnancy and using power $80 \%$, the study sample size was $93^{16}$. Data were sorted, scrutinized and then analyzed in excel, SPSS version 20.0 using descriptive statistics, frequency, significance level less than 0.05 and correlation in linear regression models. The open ended questions were grouped and categorized. Verbal consent was taken and assured them for anonymity and confidentiality. The article was finalized for study after being satisfied and ethically considered by Institutional review committee of Nepalgunj Medical College Teaching Hospital (NGMCTH), Kohalpur.

\section{RESULTS}

During the study period, incidence proportion of pre eclampsia (36\%) was found to be the major hypertensive disorder among study population as shown in figure no. 1 . Similarly table I Shows that age distribution for HDP comprised maximum (57\%) in 20-29 years whereas minimum (8.6\%) in $40-49$ years.

- Pre eclamsia $\square$ Eclampsia $\square$ Gest. HTN $\square \mathrm{PIH}=$ Chr. HTN

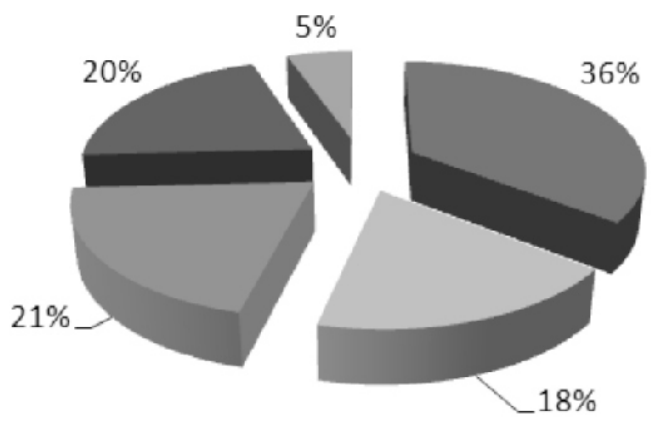

Figure 1 


\begin{tabular}{|c|c|c|}
\hline Reproductive & Frequency & (N)\% \\
\hline age group & & \\
\hline $15-19$ & 12 & 12.95 \\
\hline $20-29$ & 53 & 57.0 \\
\hline $30-39$ & 20 & 21.5 \\
\hline $40-49$ & 8 & 8.6 \\
\hline
\end{tabular}

Table no.I

It was also observed that residential distribution was slightly higher in urban for hypertensive disorder during pregnancy, i.e $51.65 \%$ from urban population and $48.40 \%$ from rural population which seemed to be linked with confounding potentials (high carb fat diet, high intake of salt, sedentary life style, socioeconomic status etc.) responsible for rise in blood pressure in pregnant women belonging to urban area.

Table II and III shows that reproductive attributes were not significant associations although nulii parity and third trimester had greater chance of developing hypertension during pregnancy. It was observed that 41 and 29 respondents were categorized as obese and overweight respectively whereas only 18 and 5 respondents were belonged to normal and underweight respectively among total population.

Figure 2. shows that $48 \%$ pregnant women were unaware about cause of high BP whereas $37 \%$ and $15 \%$ of women agreed that lack of exercise and high salt diet respectively were major cause of rise in BP during pregnancy. These risk factors contributed to be highly significant relationship among pregnant women in the study population.

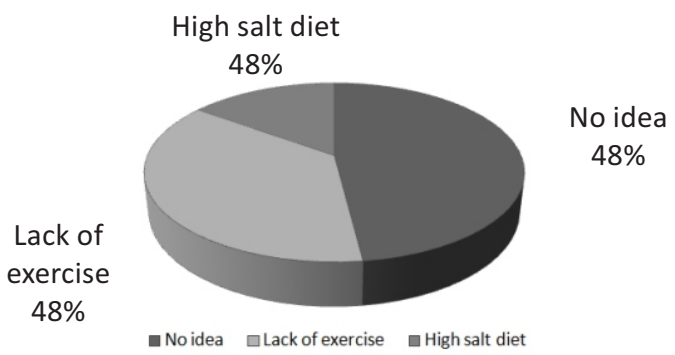
population
Figure 2: Reason behind high blood pressure in total

Lack of exercise

Total agreed pregnant women $=26$

Actual followers yes $=10$

$$
\text { no }=16
$$

High salt diet

Total agreed pregnant women $=11$

Actual followers yes $=5$

$$
\text { no }=6
$$

According to figure no.3, 32.3\% women were agreed that they had knowledge ontaking low salt diet while other were taking normal as well as high salt diet and found to be highly significant risk factor for rise in blood pressure. Similarly, only $14.0 \%$ were aware of doing regular exercise while rests of $86.0 \%$ were not doing any exercise.

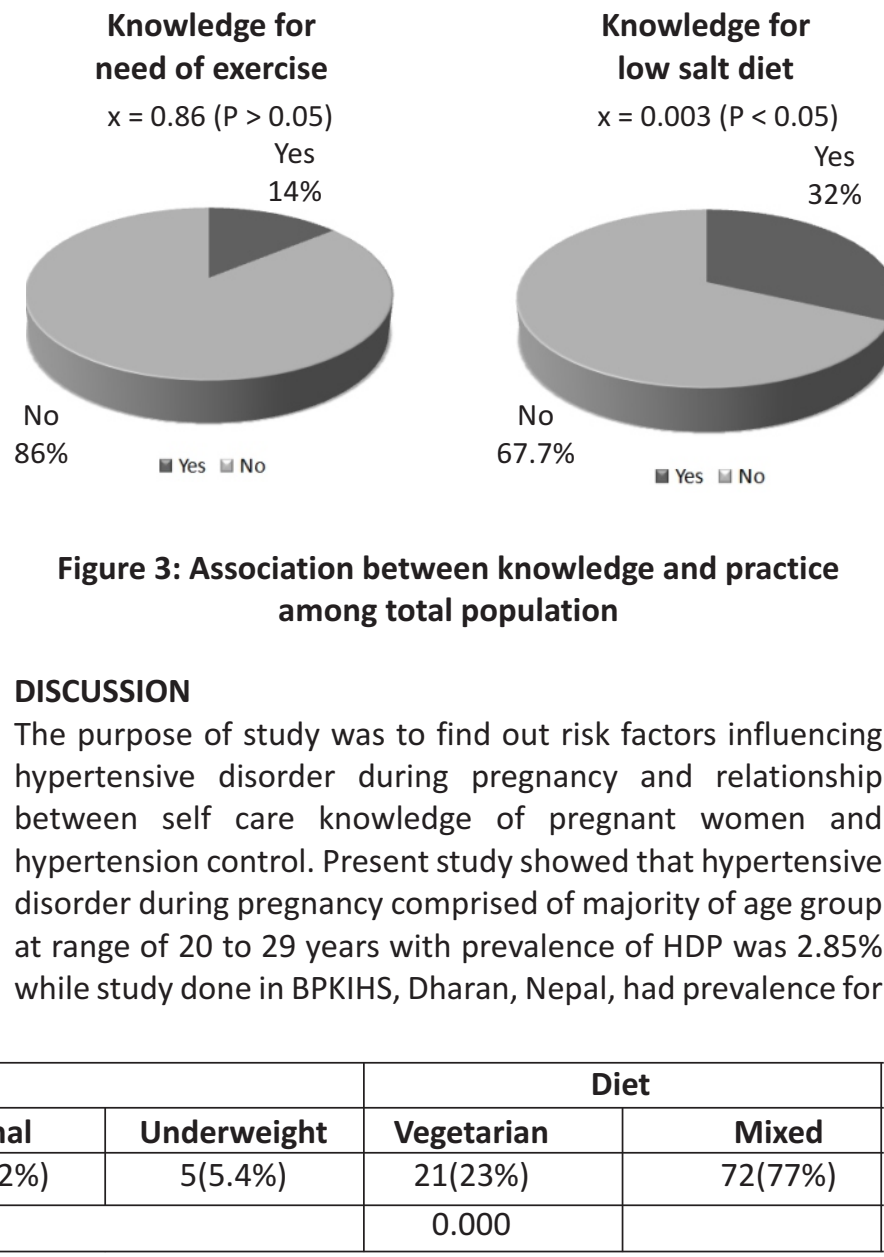

Table no. II

\begin{tabular}{|l|c|c|c|c|c|c|}
\hline \multirow{2}{*}{ Variables } & \multicolumn{2}{|c|}{ ANC Visit } & \multicolumn{2}{c|}{ Trimester } & \multicolumn{2}{c|}{ Parity } \\
\cline { 2 - 7 } & Booked & Unbooked & $2^{\text {nd }}$ & $\mathbf{3}^{\text {rd }}$ & Nulli & Multi \\
\hline N (\%) & $50(54 \%)$ & $44(46 \%)$ & $32(34.4 \%)$ & $61(65.6 \%)$ & $57(61.3 \%)$ & 0.50 \\
\hline P value & 0.001 & 0.26 & & $38.7 \%)$ \\
\hline
\end{tabular}

Table no. II 
HDP was $27.1 \%^{12}$. According to Ethiopian journal of health science, incidence hypertension during pregnancy increases with age and parity and multiple pregnancies where majority of hypertensive disorder $83(52.5 \%)$ were range at $25-34$ years $^{13}$. Pregnant women $(51.65 \%)$ residing urban area were opt to have greater tendency for developing hypertension than pregnant women belonged to rural area (48.40\%). Most of the pregnant women were nulliparous $61.3 \%$ and showed to be statistically significant association with severity of disease $(p=$ 0.001 ) which is higher than the report of $44.1 \%$ from the university of calabar, south Nigeria ${ }^{14}$.

According to the reason behind rise in blood pressure, $37 \%$ and $15 \%$ of pregnant women knew that lack of exercise and high salt diet respectively were the major contribution for rise in blood pressure. However, $48 \%$ of respondents among total population still had no idea about rise in Blood pressure during pregnancy. Present study revealed similar background with the study from Bindura district, University of health science, Zimbabwe where $55.1 \%$ respondents demonstrated knowledge of high salt diet contributes HDP. This relationship had statistically highly significant association with HDP in present study. Therefore, continue practice on danger of salt consumption and lack of exercise as a predisposing factor for HDP in some susceptible pregnant women is necessary to reduce incidence of hypertension during pregnancy ${ }^{15}$.

There was a huge gap between self care knowledge and preventive practices among pregnant women. Only $14 \%$ of the pregnant women had knowledge that exercise during pregnancy is necessary to prevent high blood pressure and despite of those who had knowledge about exercise were not following it on regular basis. Meanwhile, only $32 \%$ of pregnant women were aware of taking low salt diet among total population who agreed that high salt intake was major cause of rise in blood pressure. A study from Banaras Hindu University reflected similar result with present study in regards of self care knowledge and practices to prevent $\mathrm{HDP}^{10}$.

Pregnant women with less knowledge of risk factors such as obesity and the need to reduce weight further inquiries into the women's perceptions on weight gain and obesity. The findings would clearly guide on any misconceptions while strengthening self care knowledge in this regard.

\section{CONCLUSION}

Hypertensive disorder during pregnancy is one of the major complication following maternal and neonatal mortality and morbidity. Urban residence with high socio-economic class, rural residence with marginalized caste, illiteracy, nulli parity, high BMI level, lack of exercise, consumption of unhealthy and high salt diet were identifiable independent risk factors in this study. The major risk factor of rise in blood pressure was lack of exercise and high salt diet for the reason behind rise in blood pressure. Despite of having knowledge about risk factors to prevent and control hypertension in some pregnant women, they were still reluctant to practice their knowledge in day to day basis. So, understanding associated risk factor and developing self care knowledge regarding hypertension during pregnancy is a mandatory tool for controlling high blood pressure. Considering the findings observed in present study, to educate the pregnant women on identifying risk factors of HDP and also motivate them to take preventive measures as a compulsory requirement.

\section{REFERENCES}

1. WHO pregnancy world health organization.[Online] https://www.who.int/topics/pregnancy/en/.

2. Factsheet about maternal mortality WHO guidance, updates bulletin, 18 feb 2018).

3. Pregnancy Induced Hypertension Including Eclampsia, Obstetrics and Gynecological Emergencies, 2006 . http://my.clevelandclinic.org/health/.

4. Swarayi I. The Relationship Between Pregnancy Induced Hypertension (PIH) Self Care Knowledge and Hypertension Control Among Pregnant Mothers Aged 18 to 49 Years in Bindura District, March, 2010.

5. Lindheimer MD, Taler SJ, Cunningham FG. Hypertension in pregnancy. J Am Soc Hypertens 2008;2:484-94.

6. Cnattingius $S$, Bergstrom R, Lipworth L, Kramer MS. Pre pregnancy weight and the risk of adverse pregnancy outcomes. N Engl J Med. 1998;338:147-152.

7. E c I a m p i a W i kipedia [o n I i n e ] https://en.wikipedia.org/wiki/Eclampsia.

8. Guideline for blood pressure classification according JNC 8 blood pressure (American Heart Association And American Stroke Association ).

9. Singh V, Srivastava M. Associated risk factors with pregnancyinduced hypertension: A hospital-based KAP study. Int J Med Public Health 2015;5:59-62.

10. Nutrition - Body mass index - B M I http://www.euro.who.int/en/health-topics/diseaseprevention/nutrition/a-healthy-lifestyle/body-mass-index-bmi

11. Oken E, Taveras EM, Kleinman KP, Rich-Edwards JW, Gillman MW. Gestational weight gain and child adiposity at age 3 years. American Journal of Obstetrics and Gynecology. 2007;196:322.

12. Khadka $\mathrm{M}$ et al. Evaluation of associated risk factors of near miss obstetrics cases at BPKIHS,Dharan,Nepal. Int J Reprod coracept Obstet Gynecol. 2018 Feb;7(2):xxx-xxx.

13. Zenebe Wolde, Hailemariam Segni, Mirkuzie Woldie Hypertensive Disorders of Pregnancy in Jimma University Specialized Hospital Ethiop J Health Sci. 2011 Nov; 21(3): 147-154.

14. Mary Esien Kooffreh ${ }^{1}$, Mabel Ekott ${ }^{2}$, Dorcas O Ekpoudom The prevalence of pre-eclampsia among pregnant women in the University of Calabar Teaching Hospital, Calabar 2014 | Volume :3;133-136.

15. P.I the relationship between pregnancy induced hypertension self care knowledge and hypertension control among Pregnant mothers aged 18 to 49 years in bindura district UNIVERSITY OF ZIMBABWE; 32015. 